\title{
Influence of Pilate Therapy and Conventional Therapy in Post Natal Women with Back Pain
}

\author{
Suraj B. Kanase ${ }^{1 *}$ and Sanjay Kumar Patil ${ }^{2}$ \\ 'Krishna College of Physiotherapy, Krishna Institute of Medical Sciences Deemed to be University, Karad - 415110, \\ Maharashtra, India; drsurajkanase7@gmail.com \\ 2Department of Obg and Gynaecology, Krishna Institute of Medical Sciences Deemed to be University, \\ Karad - 415110, Maharashtra, India
}

\begin{abstract}
Background: Post-partum period is challenging for every woman. It usually starts from delivery and ends by 42 days. In majority of women, complications like hemorrhage, DVT, pulmonary embolism, edema in hand and ankle joints, puerperal infection, problems in breast feeding, kypho-scoliosis and backache arise. Postnatal low back pain and pelvic pain are common problems in the postpartum period; these could vary from mild problems to disability. The incidence of postnatal LBP is very high from $21 \%$ to $82 \%$ in the fisco year post-partum. Remission of pain occurred in 51\% at 1 month and $78 \%$ at 6 months in CS group, while in the normal vaginal delivery group $55 \%$ at 1 month and $85 \%$ in the $6^{\text {th }}$ month had remission of pain. Reoccurrence of pain is common in postnatal period. Physiotherapy has shown to have influence on various problems arising in post-natal period. Health literature listed out various conventional treatment approaches for back pain which includes exercises, yoga, core stability, walking, running, aquatic exercise and aerobics. Pilate therapy focuses on improving the body's core and makes it more flexible and stronger. Pilates has been found to be effective in neuromuscular problems. Its effect in post natal women is a research area. Its effect over conventional therapy needs to be evaluated for better patient care. Method: 494 subjects were included according to criteria. Subjects were allotted into two groups. Group A: Pilates and Group B: Conventional. Interventions were given for 6 weeks and changes in Visual Analogue Scale, Modified Schober Test, Manual Muscle Testing, Oswestry Low Back Disability were noted. Result: For pre and post interventional analysis between the groups, student's t-test was used. The results showed significant improvement with Pilates therapy than conventional training in reducing back pain, increasing abdominal muscle strength and improving quality of life. Conclusion: Pilates therapy reduced back pain than conventional therapy in post natal women.
\end{abstract}

Keywords: Back Pain, Conventional Therapy, Pilates, Post Natal

\section{Introduction}

The postnatal period is defined as the first six weeks after birth. It has importance in consideration to the health and survival of a mother and her baby ${ }^{1}$. It lasts for approximately 6 weeks, during which the changes brought about by pregnancy gets resolved and a woman adjusts herself for the new responsibilities of motherhood. Majority of women suffer from Lumbo-pelvic pain ( $45 \%$ of pregnant women and $25 \%$ women post-partum $)^{2}$. European studies show that pregnancy relayed low back pain very common in almost $60-70 \%$. Hippocrates in early $400 \mathrm{BC}$ has recognized about pregnancy related back pain. He found that during the first parturition there was widening of pubis symphysis which remained permanent and in fact helped in subsequent childbirths. The mechanism of pelvic girdle pain is still a research question. The physiological changes that occur during pregnancy induce a lot of fatigue. Weight gain, stretching of muscles and shift of center of gravity are the main reasons behind it. A wide variety of problems arise in post natal period. Back pain is very common. Besides this, bowel issues, psychological problems and anemia are also seen in few women ${ }^{3}$.

In study conducted by F. Turgutet, et al., they found that prevalence of low back pain was higher $(59.1 \%)$ at the time of delivery whereas more than $40 \%$ of women had pain even after 6 months post partum ${ }^{4}$. There are various predisposing factors for back pain. Few of them are: Young age, more body mass index, previous history of low back pain during childbirth,

${ }^{*}$ Author for correspondence 
known case of hyper mobility and mutliparous 5 . Most of the times, post partum pain remains unevaluated and not managed properly. This could finally influence the outcome in those women. As postnatal period is a challenging phase for any woman it makes her prone for many dysfunctions. Physical therapy role needs to be evaluated. Back pain is a common issue in postpartum period. If it is not managed at right time, it can lead to further complication and disorders. Physiotherapy has shown to improve trunk control in individuals where muscles are paralysed or weak ${ }^{6}$. Appropriate management tool needs to be formed. There is no uniformity in the practice of postnatal care throughout. There is evidence about importance of physical therapy in them but it needs to be evaluated in terms of pattern of practice and find out some basic guidelines that can be used everywhere. The objectives of the study were to see the effect of Pilate therapy and conventional therapy on low back pain in these women's.

\section{Materials and Methods}

An experimental study was carried out with one group receiving conventional therapy and another group Pilate therapy. It was a randomized clinical trial where Post natal women was allocated to either of control or study group randomly and were assigned conventional and Pilate therapy respectively. 494 subjects were included in this study. After baseline assessment, computer generated random numbers was used to allocate the intervention. There were four outcome measures used: To assess low back pain: Visual analogue scale, To assess lumbar range of motion: Modified Schober Test, To assess core muscle strength: Manual muscle testing, To assess quality of life: Oswestry Low Back Disability. The obstetrics and gynaecology department from Krishna Hospital Karad was explained about topic to make them aware about the requirements of subjects and infrastructure required so that they can refer/direct the subjects to me. Once the subject is fulfilling the criterias she was explained about the study. She was given detail information about the study. Subjects were instructed about pattern of treatment, time duration of treatment, clothes to be worn during treatment sessions, time interval to be maintained between breakfast, lunch and treatment. About how the sessions will go on, rest intervals in between, ending the session if any discomforts.

\section{Results}

\subsection{For Low Back Pain with Visual Analogue Scale (After 6 Weeks)}

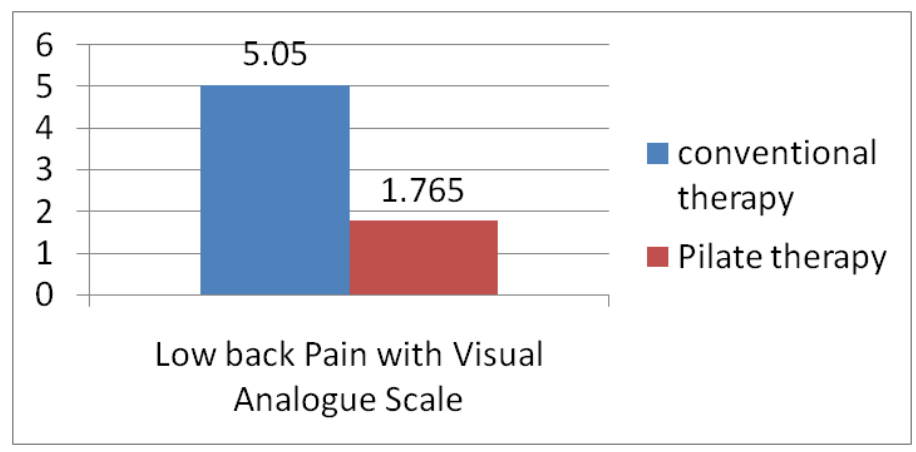

$P$ value is $<0.0001$, considered extremely significant.

\subsection{To Assess Lumbar Range of Motion: Modified Schober Test (after 6 weeks)}

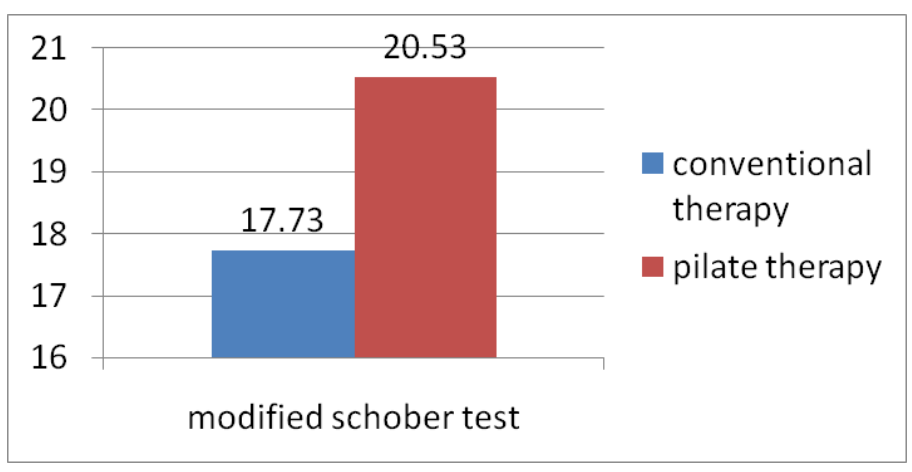

$\mathrm{t}=63.43$ and $\mathrm{P}$ value is $<0.0001$, considered extremely significant.

\subsection{To Assess Core Muscle Strength: Manual Muscle Testing (after 6 weeks)}

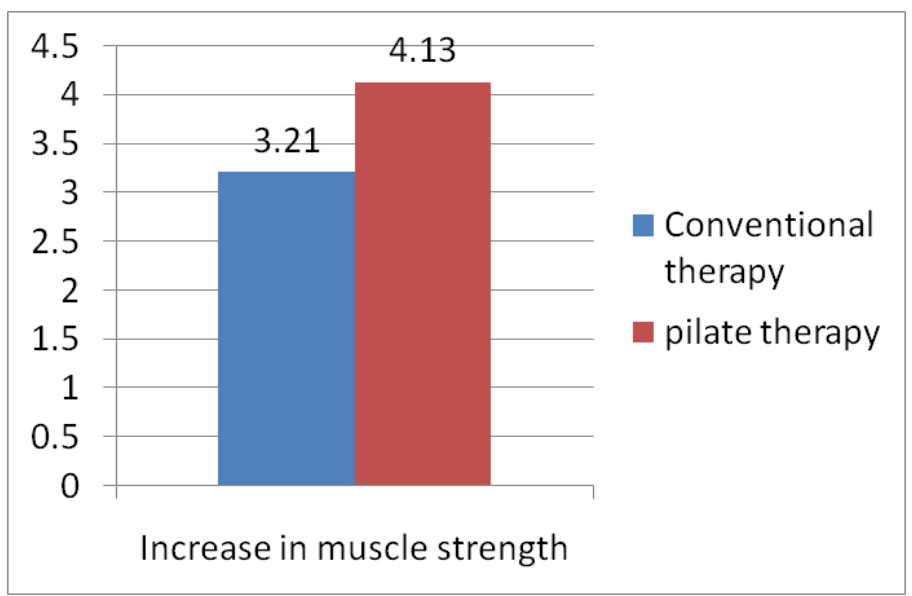

$\mathrm{t}=27.51$ and $\mathrm{P}$ value is $<0.0001$, considered extremely significant. 


\subsection{To Assess Quality of Life: Oswestry Low Back Disability (after 6 weeks)}

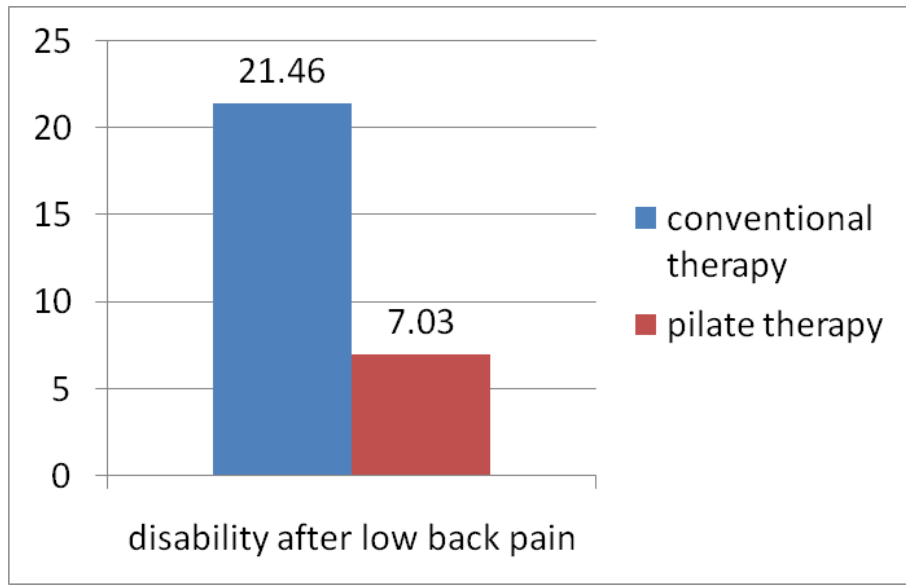

$\mathrm{t}=89.63$ and $\mathrm{P}$ value is $<0.0001$, considered extremely significant

\section{Discussion}

The present study was carried out to find out whether Pilates therapy has any influence of back pain in post-natal women. The prevalence of back pain is high in these women. Literature suggests that some women tend to have it even after a year of postpartum. The study focused on finding the pain status, abdominal muscle strength, lumbar range of motion and quality of life after post natal period.

\subsection{Back Pain}

Pilates consists of exercises which a im to improve neuromuscular control. Segmental stabilization and neuromuscular control were the possible mechanism which helped in reducing pain ${ }^{7}$. The established neuromuscular control must have helped in reducing pain. This establishes stability in lower abdominal muscles during lower limb movements. Pilate therapy improves balance within the spine by distributing equal pressure on every disc which allows normal cushion effect on the vertebrae's. This will make movements more powerful and efficient.

Pilates work on deep abdominal muscles and the pelvic floor to both contract and release - which is a sign of strength. These muscles work like a brace to lift and support the organs and protect and stabilize the back ${ }^{8}$. This mechanism also might have helped in reducing low back pain.

\subsection{Lumbar Range of Motion}

Static and dynamic strengthening exercises used in Pilates have shown to be effective in improving stability in core muscles of spine. The improved strength and extensibility has shown direct influence of lumbar range of motion. Dynamic exercises strengthen the spinal column and supporting structures ${ }^{8}$. The core muscles support the spine. Pilates concentrates on strengthening of these muscles which in turn helps to achieve the desired movement. Pilates improves balance and gait not only through core strengthening but because of its focus on alignment and whole body exercises ${ }^{9} .6$ weeks training program was based on the conceptual framework outlined originally by Pilates ${ }^{10}$. Additionally it was a whole body program. Consistent practice might have helped to improve the spine range of motion. Conventional training lacked in this practice.

\subsection{Muscle Strength}

Abdominal muscles are weakened during the course of pregnancy. Reduced muscle strength could be a risk factor for back pain. Pilates concentrates on the centre of the body from which all movement stems. Core strength is a key factor in decreasing back and hip pain, decreasing pelvic floor dysfunction and is the area from which explosive movement derives, hence its nickname "the powerhouse". In Pilate, diagonal and spiral movements of trunk occur and are performed slowly and with concentric contractions ${ }^{11}$. Hypertrophy of abdominal muscles is achieved due to isometric and eccentric contractions performed on mat ${ }^{12}$. Core muscles provide integrity to the spine. As Pilates improves core muscles, the spinal alignment is improved and in turn helps to reduce pain.

\subsection{Quality of Life}

Low back pain disturbs the activities of daily living in post natal women. The structural and mechanical impairments put lot of stress on muscles and mind of a woman. This directly disturbs the quality of living in them. Pilates has shown to improve disturbed sleep in sedentary people thereby enhancing their quality of living ${ }^{13}$. Pilates has shown to lower the level of depression, anxiety and quality in obese womens ${ }^{14}$. The exercises used in Pilates have shown to increase the bone mineral density, walking distance and beneficial to relive pain ${ }^{15}$. Benefit of body awareness, the inward focus and use of breath from Pilates can down-regulate the nervous system. This, in turn, can take you out of fight-or-flight mode, lower cortisol and decrease stress over time ${ }^{16}$. Pilate therapy has also shown to boost the immune system ${ }^{17}$. Studies which were conducted to explore benefits of Pilates have found that subjects experienced a reduction in anxiety, fatigue and depressive symptoms and a release of negative thought patterns ${ }^{18}$. These factors must have helped to improve quality of life in these women. 


\section{Conclusion}

The study concluded that Pilate's therapy reduces low back pain in post natal women when compared with conventional exercises. It has been shown to enhance muscle strength, increase range of motion of lumbar spine which will reduce the low back pain and improved quality of living in these women.

\section{Acknowledgement}

I would sincerely like to thank KIMSDTBU who provided me with the opportunity to conduct this study. I express my gratitude to Dr. Sanjay Kumar Patil sir for helping and guiding me in this study. I would like to thank Dr. G. Varadharajulu, Dean of Physiotherapy College for being constant source of support.

\section{References}

1. Warren C, Daly P. Postnatal Care. Section 3, Chapter 4; 2014. p. $80-90$.

2. Ehsani F, Sahebi N, Shanbehzadeh S, Arab AM, Shah Ali S. Stabilization exercise affects function of transverse abdominis and pelvic floor muscles in women with postpartum lumbopelvic pain: A double-blinded randomized clinical trial study. International Urogynecology Journal. 2020 Jan; 31(1):197-204. PMid: 31016337. https://doi.org/10.1007/s00192-019-03877-1

3. Pain PO, Post I. Joshi S, Parikh. S2.

4. Turgut F, Turgut M, Çetinşahin M. A prospective study of persistent back pain after pregnancy. European Journal of Obstetrics and Gynecology and Reproductive Biology. 1998 Sep 1; 80(1):458. https://doi.org/10.1016/S0301-2115(98)00080-3

5. Cody JD, Richardson K, Moehrer B, Hextall A, Glanzener CM. Oestrogens for urinary stress incontinence in women. Cochrane Database Syst Rev. 2009; 10:CD001405.

6. Khichadiya PM, Kanase SB. Effect of specific transverse abdominal muscle strengthening and conventional therapy for trunk control in paraplegic subjects. 2017 Apr; 11(2):2184. https://doi. org/10.5958/0973-5674.2017.00058.2

7. Moon HJ, Choi KH, Kim DH, Kim HJ, Cho YK, Lee KH, Kim JH, Choi YJ. Effect of lumbar stabilization and dynamic lumbar strengthening exercises in patients with chronic low back pain. Annals of Rehabilitation Medicine. 2013 Feb; 37(1):110. PMid: 23525973 PMCid: PMC3604220. https://doi.org/10.5535/ arm.2013.37.1.110
8. Gladwell V, Head S, Haggar M, Beneke R. Does a program of Pilates improve chronic non-specific low back pain? Journal of Sport Rehabilitation. 2006 Nov 1; 15(4):338-50. https://doi.org/10.1123/jsr.15.4.338

9. Hyun J, Hwangbo K, Lee CW. The effects of Pilates mat exercise on the balance ability of elderly females. Journal of Physical Therapy Science. 2014; 26(2):291-3. PMid: 24648651 PMCid: PMC3944308. https://doi.org/10.1589/jpts.26.291

10. Pilates JH, Miller WJ. Return to life through contrology. Ravenio Books; 1945.

11. Penelope L. Updating the principles of the Pilates method-Part 2. Journal of Bodywork and Movement Therapies. 2002; 2(6):94101. https://doi.org/10.1054/jbmt.2002.0289

12. Hather BM, Tesch PA, Buchanan P, Dudley GA. Influence of eccentric actions on skeletal muscle adaptations to resistance training. Acta Physiologica Scandinavica. 1991 Oct; 143(2):17785. PMid: 1835816. https://doi.org/10.1111/j.1748-1716.1991. tb09219.x

13. Leopoldino AA, Avelar NC, Passos Jr GB, Santana Jr NÁ, Teixeira Jr VP, de Lima VP, de Melo Vitorino DF. Effect of Pilates on sleep quality and quality of life of sedentary population. Journal of Bodywork and Movement Therapies. 2013 Jan 1; 17(1):5-10. PMid: 23294677. https://doi.org/10.1016/j.jbmt.2012.10.001

14. Vancini RL, Rayes AB, Lira CA, Sarro KJ, Andrade MS. Pilates and aerobic training improve levels of depression, anxiety and quality of life in overweight and obese individuals. Arquivos de Neuro-Psiquiatria. 2017; 75:850-7. PMid: 29236887. https://doi.org/10.1590/0004-282x20170149

15. Angin E, Erden Z, Can F. The effects of clinical Pilates exercises on bone mineral density, physical performance and quality of life of women with postmenopausal osteoporosis. Journal of Back and Musculoskeletal Rehabilitation. 2015 Jan 1; 28(4):849-58. PMid: 26406222. https://doi.org/10.3233/BMR-150604

16. Ahmadi $\mathrm{H}$, Mehravar MR. The effect of an eight-week Pilates exercise regimen on stress management and cortisol levels in sedentary women. Journal of Physical Activity and Hormones. 2019 Dec $1 ; 3(4): 37-52$.

17. Back SG. Effects of using prop for con vergence Pilates met exercise on the immunoglobulin in middle-aged women. Journal of the Korea Convergence Society. 2015; 6(5):329-36. https://doi. org/10.15207/JKCS.2015.6.5.329

18. Memmedova K. Impact of Pilates on anxiety attention, motivation, cognitive function and achievement of students: Structural modeling. Procedia-Social and Behavioral Sciences. 2015 May 13; 186:544-8. https://doi.org/10.1016/j.sbspro.2015.04.009 